\title{
105 - Behavioral and Psychological Symptoms of Dementia: Novel modes of Treatment and Care Delivery
}

Chairperson:

Melanie T. Gentry MD

Assistant Professor in Psychiatry

Mayo Clinic, Rochester, MN

Janette Leal MD

Instructor in Psychiatry

Mayo Clinic, Rochester, MN

Joshua Baruth, MD, PhD

Fellow, Geriatric Psychiatry

Mayo Clinic, Rochester, MN

Jaclyn Lindsey MD

Resident, Adult Psychiatry

Mayo Clinic, Rochester, MN

As the World Population continues to expand, the number of individuals affected by Alzheimer's Disease and other Dementias is also rapidly increasing. The number of individuals living with dementia is expected to increase to 131.5 million by 2050. (Prince et al., 2015) Behavioral and Psychological Symptoms of Dementia (BPSD) are highly prevalent, affecting up to $80 \%$ of individuals with dementia. (Garre-Olmo, Lopez-Pousa et al. 2010) BPSD has significant negative consequences for morbidity, mortality, and quality of life in those with dementia. Unfortunately, available treatments for BPSD are often limited or inconsistent in their efficacy and prone to severe adverse drug effects such as increased mortality.(Schneider, Dagerman et al. 2006) It is increasingly clear that current approaches are inadequate and novel treatments for BPSD need to be explored and researched. This symposium will draw on the available research literature as well as clinical experiences and case examples to provide up to date information on some of the newest treatment options available for BPSD. Dr. Melanie Gentry will discuss the use of telemedicine and other forms of technology to improve diagnosis and treatment of individuals with BPSD. Dr. Baruth will discuss the rapidly growing interest in the use of medical marijuana and cannabinoids in the management of BPSD. Dr. Lindsey will review the evidence for neuromodulation techniques including electroconvulsive therapy (ECT) and repetitive transcranial magnetic stimulation (rTMS). Dr. Leal will review environmental and behaviorally based interventions. Garre-Olmo, J., S. Lopez-Pousa, J. Vilalta-Franch, M. de Gracia Blanco and A. B. Vilarrasa (2010). "Grouping and trajectories of the neuropsychiatric symptoms in patients with Alzheimer's disease, part I: symptom clusters." J Alzheimers Dis 22(4): 1157-1167.

Prince, M., Wimo, A., Guerchet, M., Ali, G.C., Wu, Y.T., and Prina, M. (2015). World Alzheimer Report 2015. The global impact of dementia: an analysis of prevalence, incidence, cost and trends [Online]. London: Alzheimer's Disease International Available: https://www.alz.co.uk/research/WorldAlzheimerReport2015.pdf [Accessed 2020 Feb 12].

Schneider, L. S., K. Dagerman and P. S. Insel (2006). "Efficacy and adverse effects of atypical antipsychotics for dementia: Meta-analysis of randomized, placebo-controlled trials." American Journal of Geriatric Psychiatry 14(3): 191-210.

Behavioral and Psychological Symptoms of Dementia: Novel modes of Treatment and Care Delivery Speakers: Melanie T. Gentry MD Assistant Professor in Psychiatry 